\title{
ANALISA DETERMINAN PEMILIHAN ALAT KONTRASEPSI INTRA UTERI DEVICE (IUD)
}

\author{
Murti Wuryani $^{1}$, Dewi Ratna ${ }^{2}$ \\ ${ }^{1}$ Akademi Kebidanan Yayasan Konawe \\ E-mail : murtiinara@gmail.com
}

\begin{abstract}
ABSTRAK
Salah satu strategi dari pelaksanaan program KB sendiri seperti tercantum dalam rencana pembangunan jangka menengah (RPJM) tahun 2004-2009 adalah meningkatnya penggunaan metode kontrasepsi jangka panjang (MKJP) seperti IUD (Intra Uterine Device), implan susuk dan sterilisasi. Di Indonesia pada tahun 2016 kontrasepsi yang paling tinggi digunakan adalah suntik sebanyak 53,9\%, dan IUD kontrasepsi terendah sebanyak 6,6\% (BKKBN, 2016). Tujuan penelitian adalah untuk mengetahui faktor yang berhubungan dengan pemilihan alat kontrasepsi IUD di Wilayah Kerja Puskesmas Uepai Kabupaten Konawe. Metode penelitian dengan pendekatan kuantitatif menggunakan rancangan cross sectional. Sampel dalam penelitian ini adalah sebagian dari Pasangan Usia Subur (PUS), yang sudah menikah dan masih aktif menjadi Akseptor KB (IUD dan Non IUD) yang tinggal di Wilayah Kerja UPTD Puskesmas Uepai Kabupaten Konawe tahun 2018 berjumlah 94 sampel, instrument yang digunakan adalah kuesioner, hasil penelitian di analisa menggunakan chi-square. Hasil penelitian menunjukkan ada hubungan pengetahuan, pendidikan, sarana dan prasarana, sumber informasi, dukungan keluarga dan dukungan tenaga kesehatan dengan pemilihan alat kontrasepsi IUD dengan nilai $p$ value masing-masing variabel $<0.05$. Kesimpulan dalam penelitian faktor yang berhubungan dengan pemilihan alkon IUD adalah pengetahuan, pendidikan, sarana dan prasarana, sumber informasi, dukungan keluarga dan dukungan tenaga kesehatan.
\end{abstract}

Kata Kunci : Alat kontrasepsi; IUD

\section{THE RELATED FACTORS OF INTRA UTERI DEVICE (IUD) CONTRACEPTION AT DISTRICT HEALTH CENTRE OF UEPAI IN KONAWE REGENCY}

\begin{abstract}
One of the strategies of implementation of family planning program as stated in medium term development plan (RPJM) year 2004-2009 is increasing the use of long term contraception method (MKJP) such as IUD (Intra Uterine Device), implant and sterilization. In Indonesia in 2016 the highest contraceptive use was injecting $53.9 \%$, and the lowest contraceptive IUD by $6.6 \%$. The objective of the research was to know the factors related to the selection of IUD contraception at district health centre of Uepai in Konawe Regency. Research method used quantitative approach using cross sectional design. Sample in this research was couples of childbearing age, married and still actively become family planning acceptors (IUD and Non IUD) living at district health centre of Uepai in Konawe Regency in 2018 with amount 94 samples, instrument used was questionaire and the results of the analysis used chi-square analysis. The result of research is knowledge, education, facilities and infrastructure, information source, family support and health personnel support with IUD contraception choice with $p$ value of each variable $<0.05$. The conclusions in the research of factors related to the selection of IUD contraception are knowledge, education, facilities and infrastructure, information sources, family support and health personnel support.
\end{abstract}

Keywords: Intra Uteri Device, contraception, family planning. 


\section{Pendahuluan}

Laju pertumbuhan penduduk Indonesia dapat dikendalikan dengan mengontrol faktorfaktor yang mempengaruhi pertumbuhan penduduk yaitu melalui progam keluarga berencana untuk mengendalikan fertilitas. Untuk menanggulangi masalah tersebut pemerintah telah mencanangkan program keluarga berencana (KB) sebagai program Nasional untuk meningkatkan kepedulian dan peran serta masyarakat melalui pengaturan jumlah kelahiran, pembinaan kesejahteraan keluarga dalam upaya untuk mewujudkan keluarga kecil bahagia dan sejahtera sehingga dapat meningkatkan kualitas penduduk (BKKBN, 2012).

Kesadaran akan pentingnya kontrasepsi di Indonesia perlu ditingkatkan untuk mencegah terjadinya ledakan penduduk yang merupakan salah satu permasalahan global yang muncul diseluruh dunia, selain isu pemanasan global, krisis ekonomi, masalah pangan serta menurunnya tingkat kesehatan penduduk. Kekawatiran akan terjadi ledakan penduduk pada tahun 2020 mendorong pemerintah Indonesia menyusun beberapa kebijakan penting karena penduduk yang besar tanpa disertai kualitas yang memadai akan menjadi beban pembangunan serta menyulitkan pemerintah dalam meningkatkan pertumbuhan ekonomi dan pembangunan Nasional (Emon, 2015).

Salah satu strategi dari pelaksanaan program KB sendiri seperti tercantum dalam rencana pembangunan jangka menengah (RPJM) tahun 2004-2009 adalah meningkatnya penggunaan metode kontrasepsi jangka panjang (MKJP) seperti IUD (Intra Uterine Device), implan susuk dan sterilisasi.

Intra Uterine Devices (IUD) merupakan salah satu metode kontrasepsi yang cukup aman dan paling dianjurkan dalam Program Nasional Keluarga Berencana di Indonesia. Karena mempunyai efektifitas 97 - $99 \%$ untuk mencegah kehamilan dan pemakaian jangka panjang. Intra Uterine Devices (IUD) bagi banyak kaum wanita merupakan alat kontrasepsi yang terbaik. Alat ini sangat efektif dan tidak perlu di ingat setiap hari seperti halnya pil. Bagi ibu yang menyusui, IUD tidak akan mempengaruhi (ASI), kelancaran ataupun kadar (ASI) (Manuaba, 2013).

Menurut Green (2005), keputusan konsumen dalam memilih metode alat kontrasepsi ini tergantung dari perilaku konsumen itu sendiri. Faktor yang dapat menjadi penyebab perilaku adalah faktor predisposing (pengetahuan, pendidikan), faktor enabling (sarana dan prasarana, sumber informasi), faktor reinforcing (dukungan tenaga kesehatan, dukungan keluarga). 
Akseptor KB IUD di Wilayah Kerja Puskesmas Uepai Kabupaten Konawe angkanya masih rendah, dimana pada tahun 2016 pengguna KB IUD 24 Orang, tahun 2017 berjumlah 24 orang dan terjadi peningkatan di tahun 2018 dari bulan Januari- April sebanyak 29 Orang. Meskipun IUD mengalami peningkatan di tahun 2018 KB IUD masih termasuk angka terendah dari seluruh jumlah penggunaan alat kontrasepsi.

Berdasarkan gambaran tersebut diatas, maka peneliti tertarik melakukan penelitian yang berjudul "Faktor-faktor yang berhubungan dengan Pemilihan Alat Kontrasepsi Intra Uteri Device (IUD) di Wilayah Kerja Puskesmas Uepai Kabupaten Konawe”.

\section{Tinjauan Teori}

\section{Pengertian IUD}

IUD adalah alat kontrasepsi modern yang telah dirancang baik bentuk, ukuran, bahan dan fungsi dan letakan di dalam kavum uteri sebagai usaha menghalangi fertilisasi dan menyulitkan telur berimplantasi dalam uterus (Hidayati, 2009).

2. Tinjauan Faktor-Faktor yang Berhubungan dengan Pemilihan Alat Kontrasepsi IUD

a. Pengetahuan

Pengetahuan adalah hasil penginderaan manusia atau hasil tahu seseorang terhadap objek melalui indra yang dimilikinya (mata, hidung, telinga, dan sebagainya) (Notoadmodjo, 2010).

b. Pendidikan

Pendidikan adalah proses pengubahan sikap seseorang atau kelompok orang dalam usaha mendewasakan manusia melalui usaha pengajaran dan pelatihan (Kamus Besar Bahasa Indonesia, 2008).

c. Sarana dan prasarana

Agar dapat melaksanakan pelayanan KB sesuai dengan metode kontrasepsi yang diberikan maka kelengkapan alat atau ketersediaan alat merupakan hal utama yang harus dimiliki oleh tempat pelayanan KB (BKKBN, 2012).

d. Sumber informasi

Sumber informasi adalah segala hal yang dapat digunakan oleh seseorang sehingga mengetahui tentang hal yang baru termasuk pemilihan alat kontrasepsi IUD dimana alat kontrasepsi IUD ini adalah salah satu alat kontrasepsi jangka panjang yang mudah dijangkau dan tidak memiliki kandungan hormon (Cahyo, 2009)

e. Dukungan keluarga 
Dukungan keluarga didefinisikan yaitu informasi verbal, sasaran, bantuan yang nyata atau tingkah laku yang diberikan oleh orang-orang yang akrab dengan subjek didalam lingkungan sosialnya atau yang berupa kehadiran dan hal yang dapat memberikan keuntungan emosional atau pengaruh pada tingkah laku penerimaannya (Era, 2017).

f. Dukungan tenaga kesehatan

Dukungan tenaga kesehatan adalah kenyamanan fisik dan psikologis, perhatian, penghargaan, maupun bantuan dalam bentuk lainnya yang diterima individu dari tenaga kesehatan. Dukungan tenaga kesehatan dapat berwujud dukungan emosional, penghargaan, instrumental, dan informasi. Tenaga kesehatan merupakan sumber dukungan sosial yang berasal dari individu lain yang sangat jarang memberi dukungan dan memiliki peran yang sangat cepat berubah (Era, 2017).

\section{Metode Penelitian}

Tempat penelitian di Wilayah Kerja Puskesmas Uepai Kab. Konawe dan dilaksanakan pada bulan Januari-April 2018. Penelitian ini menggunakan pendekatan kuantitatif dengan desain penelitian cross sectional. Sampel dalam penelitian ini adalah sebagian dari PUS yg masih aktif menjadi akseptor KB sebanyak 94 PUS. Teknik pengambilan sampel dilakukan dengan menggunakan Simple Random Sampling. Variabel yang di teliti dalam penelitian ini adalah variabel dependent (pemilihan alkon IUD) dan variabel independent (pendidikan, pengetahuan, sarana prasarana, sumber informasi, dukungan keluarga dan dukungan tenaga kesehatan). Penelitian ini di analisis menggunakan analisis univariat untuk mengetahui gambaran masing-masing variabel dan analisis bivariat untuk melihat adanya hubungan antara variabel dependent dengan variabel independent menggunakan uji statistik chi-square.

\section{Hasil Penelitian}

Tabel 1. Hubungan Pendidikan Responden Terhadap Pemilihan Alat Kontrasepsi IUD

\begin{tabular}{|c|c|c|c|c|c|c|c|}
\hline \multirow[t]{3}{*}{ Pengetahuan } & \multicolumn{4}{|c|}{ Pemilihan Alkon IUD } & \multicolumn{2}{|c|}{ Jumlah } & \multirow[t]{3}{*}{ P value } \\
\hline & \multicolumn{2}{|c|}{$\mathrm{Ya}$} & \multicolumn{2}{|c|}{ Tidak } & \multirow[b]{2}{*}{$\mathrm{n}$} & \multirow[b]{2}{*}{$\%$} & \\
\hline & $\mathrm{n}$ & $\%$ & $\mathrm{n}$ & $\%$ & & & \\
\hline Baik & 11 & 11,7 & 11 & 11,7 & 22 & 23,4 & 0,000 \\
\hline Cukup & 17 & 18,1 & 31 & 33,0 & 48 & 51,1 & \\
\hline Kurang & 1 & 1,1 & 3 & 24,5 & 24 & 25,5 & \\
\hline Jumlah & 29 & 30,9 & 65 & 69,1 & 94 & 100 & \\
\hline
\end{tabular}

Hasil uji statistik pada tabel di atas menggunakan uji chi square diperoleh nilai $p$ value $=0,000$, dengan demikian $p$ value lebih kecil dari alpha 0,05 sehingga Ha diterima, 
sehingga ada hubungan yang signifikan antara pengetahuan dengan pemilihan alat kontrasepsi IUD.

Tabel 2. Hubungan Pendidikan Responden dengan Pemilihan Alat Kontrasepsi IUD

\begin{tabular}{|c|c|c|c|c|c|c|c|}
\hline \multirow[t]{3}{*}{ Pendidikan } & \multicolumn{4}{|c|}{ Pemilihan Alkon IUD } & \multirow{2}{*}{\multicolumn{2}{|c|}{ Jumlah }} & \multirow[t]{3}{*}{$P$ value } \\
\hline & \multicolumn{2}{|c|}{$\mathrm{Ya}$} & \multicolumn{2}{|c|}{ Tidak } & & & \\
\hline & $\mathrm{n}$ & $\%$ & $\mathrm{n}$ & $\%$ & $\mathrm{n}$ & $\%$ & \\
\hline Tinggi & 17 & 18,7 & 14 & 15,5 & 31 & 34,3 & 0,002 \\
\hline Rendah & 12 & 13,5 & 51 & 52,3 & 63 & 65,7 & \\
\hline Jumlah & 29 & 32,2 & 65 & 69,1 & 94 & 100 & \\
\hline
\end{tabular}

Hasil uji statistik pada tabel di atas menggunakan uji chi square diperoleh nilai $p$ value $=0,002$, dengan demikian $p$ value lebih kecil dari alpha 0,05 Ha diterima, sehingga, ada hubungan yang signifikan antara pendidikan dengan pemilihan alat kontrasepsi IUD.

Tabel 3. Hubungan Sarana dan Prasarana dengan dengan Pemilihan Alat Kontrasepsi IUD

\begin{tabular}{|c|c|c|c|c|c|c|c|}
\hline \multirow[t]{3}{*}{ Pendidikan } & \multicolumn{4}{|c|}{ Pemilihan Alkon IUD } & \multirow{2}{*}{\multicolumn{2}{|c|}{ Jumlah }} & \multirow[t]{3}{*}{$P$ value } \\
\hline & \multicolumn{2}{|c|}{$\mathrm{Ya}$} & \multicolumn{2}{|c|}{ Tidak } & & & \\
\hline & $\mathrm{n}$ & $\%$ & $\mathrm{n}$ & $\%$ & $\mathrm{n}$ & $\%$ & \\
\hline Tinggi & 19 & 20,2 & 20 & 21 & 39 & 41,5 & 0,002 \\
\hline Rendah & 10 & 10,6 & 45 & 47,9 & 55 & 58,5 & \\
\hline Jumlah & 29 & 30,9 & 65 & 69,1 & 94 & 100 & \\
\hline
\end{tabular}

Hasil uji statistik pada tabel di atas menggunakan uji chi square diperoleh nilai $p$ value $=0,002$, dengan demikian $p$ value lebih kecil dari alpha 0,05 sehingga Ha diterima, sehingga ada hubungan yang signifikan sarana dan prasarana dengan pemilihan alat kontrasepsi IUD.

Tabel 4. Hubungan Sumber Informasi dengan Pemilihan Alat Kontrasepsi IUD

\begin{tabular}{|c|c|c|c|c|c|c|c|}
\hline \multirow[t]{3}{*}{ Sumber Informasi } & \multicolumn{4}{|c|}{ Pemilihan Alkon IUD } & \multirow{2}{*}{\multicolumn{2}{|c|}{ Jumlah }} & \multirow[t]{3}{*}{$P$ value } \\
\hline & \multicolumn{2}{|c|}{$\mathrm{Ya}$} & \multicolumn{2}{|c|}{ Tidak } & & & \\
\hline & $\mathrm{n}$ & $\%$ & $\mathrm{n}$ & $\%$ & $\mathrm{n}$ & $\%$ & \\
\hline Ada Informasi & 18 & 19,1 & 4 & 4,3 & 22 & 23,4 & 0,000 \\
\hline Tidak ada informasi & 11 & 11,7 & 61 & 64,9 & 72 & 76,6 & \\
\hline Jumlah & 29 & 30,9 & 65 & 69,1 & 94 & 100 & \\
\hline
\end{tabular}

Hasil uji statistik pada tabel di atas menggunakan uji chi square diperoleh nilai $p=$ 0,000, dengan demikian $p$ value lebih kecil dari alpha 0,05 sehingga Ha diterima, sehingga berarti ada hubungan yang signifikan antara sumber informasi dengan pemilihan alat kontrasepsi IUD. 
Tabel 5. Hubungan Dukungan Keluarga dengan Pemilihan Alat Kontrasepsi IUD

\begin{tabular}{lcccccccc}
\hline \multirow{2}{*}{ Dukungan Keluarga } & \multicolumn{3}{c}{ Pemilihan Alkon IUD } & & \multicolumn{2}{c}{ Jumlah } & \multicolumn{2}{c}{ P value } \\
\cline { 2 - 5 } & \multicolumn{2}{c}{ Ya } & & \multicolumn{2}{c}{ Tidak } & & & \\
\cline { 2 - 5 } & $\mathrm{n}$ & $\%$ & $\mathrm{n}$ & $\%$ & $\mathrm{n}$ & $\%$ & \\
\hline Mendukung & 26 & 27,2 & 10 & 10,6 & & 36 & 38,3 & 0,000 \\
Tidak Mendukung & 3 & 3,2 & 55 & 58,8 & & 58 & 61,7 & \\
Jumlah & 29 & 30,9 & 65 & 69,1 & & 94 & 100 & \\
\hline
\end{tabular}

Hasil uji statistik pada tabel di atas menggunakan uji chi square diperoleh nilai $p$ $=0,000$, dengan demikian $p$ value lebih kecil dari alpha 0,05 sehingga Ha diterima, berarti ada hubungan yang signifikan antara dukungan keluarga dengan pemilihan alat kontrasepsi IUD.

Tabel 6. Hubungan Dukungan Tenaga Kesehatan dengan Pemilihan Alat Kontrasepsi IUD

\begin{tabular}{lcccccccc}
\hline \multirow{2}{*}{$\begin{array}{c}\text { Dukungan Tenaga } \\
\text { Kesehatan }\end{array}$} & \multicolumn{4}{c}{ Pemilihan Alkon IUD } & & Jumlah & P \\
\cline { 2 - 5 } & \multicolumn{2}{c}{ Ya } & \multicolumn{2}{c}{ Tidak } & & & value \\
\cline { 2 - 5 } & $\mathrm{n}$ & $\%$ & $\mathrm{n}$ & $\%$ & $\mathrm{n}$ & $\%$ & \\
\hline Mendukung & 22 & 23,4 & 19 & 20,2 & & 41 & 43,6 & 0,000 \\
Tidak Mendukung & 7 & 7,4 & 46 & 48,9 & & 53 & 56,4 & \\
Jumlah & 29 & 30,9 & 65 & 69,1 & & 94 & 100 & \\
\hline
\end{tabular}

Hasil uji statistik pada tabel di atas menggunakan uji chi square diperoleh nilai $p=0,000$, dengan demikian $p$ value lebih kecil dari alpha 0,05, Ha diterima sehingga hubungan yang signifikan antara dukungan tenaga kesehatan dengan pemilihan alat kontrasepsi IUD.

\section{Pembahasan}

\section{Hubungan Pengetahuan Responden dengan Pemilihan Alat Kontrasepsi IUD}

Pengetahuan adalah hasil dari tahu, dan ini terjadi setelah orang melakukan pengindraan terhadap suatu objek tertentu. Pengetahuan yang rendah tentang manfaat dan tujuan pemilihan alat kontrasepsi IUD bisa menjadi penyebab gagalnya penggunaan alat kontrasepsi IUD pada PUS. Pendidikan diperkirakan ada kaitannya dengan pengetahuan PUS dalam pemilihan alat kontrasepsi IUD, hal ini dihubungkan dengan tingkat pengetahuan ibu bahwa seseorang yang berpendidikan lebih tinggi akan mempunyai pengetahuan yang lebih luas dibandingkan dengan tingkat pendidikan yang rendah (Arini H, 2012).

Penelitian ini sejalan dengan penelitian yang dilakukan (Tetty Erwana Haloha, 2011), dengan $p$ value $=0,003, \mathrm{RP}=2,40$ dengan Lower $=14,32$ dan $\mathrm{Upper}=25,90$ yang 
menyatakan ada hubungan yang signifikan antara pengetahuan dengan pemilihan alat kontrasepsi IUD.

\section{Hubungan Pendidikan Responden dengan Pemilihan Alat Kontrasepsi IUD}

Pemakaian alat kontrasepsi modern akan meningkat seiring dengan tingkat pendidikan wanita. Sedangkan menurut (SDKI, 2007), semakin tinggi tingkat pendidikan seorang wanita maka semakin banyak pula mereka mendapat pengetahuan tentang KB modern dimana wanita yang mempunyai pendidikan rendah akan lebih cenderung kurang mendapat informasi dibandingkan dengan wanita yang mempunyai pendidikan tinggi. Pendidikan mempunyai pengaruh positif terhadap tingkat pemakaian kontrasepsi. Berkaitan dengan informasi yang mereka terima dan kebutuhan untuk menunda atau membatasi jumlah anak. Wanita yang berpendidikan cenderung lebih sadar untuk menerima program KB (BKKBN, 2012). Dengan pendidikan tinggi seseorang akan cenderung mendapatkan informasi, baik dari orang lain maupun dari media massa, sebaliknya tingkat pendidikan yang kurang akan menghambat perkembangan dan sikap seseorang terhadap nilai-nilai yang baru diperkenalkan (Nursalam, 2001).

Penelitian ini sejalan dengan penelitian yang dilakukan oleh (Gita Trisna Dewi, 2015), dengan $p$ value $=0,001, \mathrm{RP}=2,13$ dengan Lower $=0,88$ dan Upper $=5,13$ yang menyatakan bahwa ada hubungan yang signifikan antara pendidikan dengan pemilihan alat kontrasepsi IUD.

\section{Hubungan Sarana dan Prasarana Responden dengan Pemilihan Alat Kontrasepsi} IUD

Agar dapat melaksanakan pelayanan KB sesuai dengan metode kontrasepsi yang diberikan maka kelengkapan alat atau ketersediaan alat merupakan hal utama yang harus dimiliki oleh tempat pelayanan KB (BKKBN, 2012). Tersedinya fasilitas kesehatan yang memadai dengan jarak yang mudah terjangkau akan memberi kemudahan bagi PUS menggunakan alat kontrasepsi IUD dan untuk mendapatkan penanganan dalam keadaan darurat. Dengan tersedianya fasilitas yang memadai akan memudahkan PUS untuk menggunakan alat kontrasepsi dari awal pemasangan kontrasepsi sampai akhir (Rukiyah, 2009).

Penelitian ini sejalan dengan penelitian yang dilakukan oleh (Sukmawati ,2011) ,dengan $p=0,000, \mathrm{RP}=5,556$ dengan Lower $=2,295$ dan Upper= 13,450 yang menyatakan bahwa ada hubungan antara kelengkapan Sarana dan Prasarana dengan pemilihan alat kontrasepsi IUD. 


\section{Hubungan Sumber Informasi Responden dengan Pemilihan Alat Kontrasepsi IUD}

Sumber informasi adalah segala hal yang dapat digunakan oleh seseorang sehingga mengetahui tentang hal yang baru termasuk pemilihan alat kontrasepsi IUD (Cahyo, 2009). Pengetahuan seseorang dapat dipengaruhi oleh sumber informasi sehingga dapat meningkatkan kemampuan berfikir. Informasi dapat diperoleh dari berbagai sumber yaitu petugas kesehatan, teman, keluarga, serta media massa. Individu yang telah memahami informasi yang telah diberikan canderung akan memberikan presepsi yang lebih baik dibandingkan yang memperoleh informasi (Notoatmodjo 2010) .

Penelitian ini sejalan dengan penelitian yang dilakukan oleh (Indah, 2011) dengan nilai $p$ value $=0,823$ yang menyatakan tidak ada hubungan sumber informasi dengan keputusan untuk menggunakan KB.

\section{Hubungan Dukungan Keluarga Responden dengan Pemilihan Alat Kontrasepsi IUD}

Menurut (Hartanto, 2003), mengatakan bahwa seorang wanita apabila menggunakan kontrasepsi tidak akan dapat dipakai apabila tidak ada kerja sama dengan suami. Hal tersebut merupakan metode kesadaran akan fertilitas yang sangat membutuhkan kerjasama dan saling percaya antara suami istri. Seorang istri dalam menggunakan kontrasepsi idealnya apabila: memilih metode kontrasepsi, saling bekerja sama dalam pemilihan/pemakaian kontrasepsi membiayai biaya untuk kontrasepsi serta sama-sama memperhatikan memperhatikan tanda bahaya dari pemakaian kontrasepsi tersebut. Dukungan keluarga sangat berperan dalam mendorong minat atau kesediaan ibu dalam menggunakan alat kontrasepsi. Keluarga bisa menjadi motivator kuat bagi ibu apabila selalu menyediakan diri untuk mendampingi atau mengantarkan ibu ke tenaga kesehatan, serta berusaha membantu mengatasi segala permasalahan ibu (Fallen, 2010).

Penelitian ini sejalan dengan penelitian yang dilaksanakan oleh (Tetty Erwani Haloho, 2011), dengan $\mathrm{p}=0,002, \mathrm{PR}=2,26$ dengan Lower $=0,93$ dan Upper $=5,51$ yang menyatakan adanya hubungan yang signifikan antara dukungan keluarga dengan pemilihan alat kontrasepsi IUD.

\section{Hubungan Dukungan Tenaga Kesehatan Responden dengan Pemilihan Alat Kontrasepsi IUD}

Untuk mengubah atau mendidik masyarakat seringkali diperlukan pengaruh dari tokoh-tokoh atau pemimpin masyarakat (community leaders), misalnya dalam masyarakat tertentu kata-kata tokoh masyarakat yang melibatkan ulama, seniman, ilmuwan, petugas kesehatan. Tergantung pada jenis masalah atau perubahan yang bersangkutan (Sarwono, 
2001). Ibu yang mendapatkan dukungan yang memadai dari tenaga kesehatan sebagai kelompok referensi, akan berhasil dalam pemilihan alat kontrasepsi IUD. Dukungan yang dilakukan secara terus menerus dan berkesinambungan sampai ibu bisa memilih alat kontrasepsi IUD. Dukungan yang diberikan dapat membantu ibu mengatasi kesulitan yang dihadapi, memungkinkan ibu untuk berhasil dalam memilih alat kontrasepsi IUD (Proverawati, 2010).

Hasil penelitian (Wiadnyana, 2005), menemukan adanya hubungan yang signifikan antara sikap petugas dengan pemanfaatan pelayanan kontrasepsi IUD dengan $\mathrm{p}=0,000, \mathrm{RP}=1,27$ dengan lower $=0,73$ dan upper $=4,31$. Wiadnyana menyarankan agar petugas kesehatan perlu lebih interest terhadap upaya pemberian pelayanan kontrasepsi IUD dalam upaya memberikan pelayanan yang terbaik pada masyarakat.

\section{Kesimpulan}

Pengetahuan, pendidikan, sarana prasarana, sumber informasi, dukungan keluarga dan dukungan tenaga kesehatan mempengaruhi pemilihan alat kontrasepsi Intra Uteri Device (IUD) di Wilayah kerja Puskesmas Uepai Kabupaten Konawe.

\section{Saran}

Berdasarkan hasil penelitian yang dilakukan dengan segala keterbatasan serta kekurangan, maka penulis dapat mengajukan saran sebagai berikut:

1. Meningkatkan melakukan penyuluhan kepada masyarakat khususnya bagi PUS (suami dan istri) agar para suami dapat memahami kontrasepsi terutama kontrasepsi IUD sehingga dia (suami) mendukung untuk menggunakan kontrasepsi IUD tersebut.

2. Bagi para keluarga agar ikut serta dalam mendukung istrinya untuk menggunakan alat kontrasepsi sebagai upaya untuk mendukung program pemerintah dalam mengatur jumlah kelahiran anak melalui penggunaan alat kontrasepsi IUD.

3. Memberikan pelayanan yang prima serta memberikan konseling kepada PUS sehingga mereka memutuskan menggunakan alat kontrasepsi IUD tidak ada unsur paksaan dari bidan atau petugas kesehatan. 


\section{Daftar Pustaka}

Anita. (2014). Faktor-faktor yang berhubungan dengan pemilihan kontrasepsi PUS di Puskesmas Damau Kabupaten Talud, 2339-1731

Arini H. (2012). Pelayanan Keluarga Berencana. Jakarta: Bina Pustaka

BKKBN. (2012). Jenis-Jenis Alat Kontrasepsi. Jakarta: BKKBN

Cahyo. (2009). Invers Emas Kaya Selangit. Yogyakarta: Laksana

Era. (2017). Pengaruh dukungan tenaga kesehatan terhadap pemberian ASI Eksklusif di Wilayah Kerja Puskesmas Sisir Kelurahan Sisir Kota Batu, 19-24

Emon, S. (2015). Perlukah Kontap Pria. Jakarta: Bina Rupa Aksara

Fallen. (2010). Catatan Kuliah Keperawatan Komunitas. Yogyakarta: Nuha Medika

Green, W, Lawrence. (2005). Health Program Planning: An Educational And Ecological Approach. Four Edition, Mcgraw-Hill, New York

Hartanto. (2003). Keluarga Berencana Dan Kontrasepsi. Jakarta: Pusat Sinar Harapan

Hidayatih. (2009). Asuhan Keperawatan pada Kehamilan Fisiologis dan Patologi. Jakarta: Salemba Medika

Indah. (2011). Sumber informasi yang mempengaruhi keputusan menjadi akseptor KB Wanita. Skripsi. Undip

Manuaba. (2013). Kapita Selekta Penatalaksanaan Obstetri Ginekologi Dan KB. Jakarta. Penerbit Buku Kedokteran EGC.

Mujiati. (2013). Penggunaan Alat Kontrasepsi. Yogyakarta: Nuha Medika

Notoadmodjo. (2010). Metodologi Penelitian Kesehatan. Edisi Revisi. Jakarta: Rineka Cipta.

Proverawati, Atikah. (2010). Panduan Memilih Kontrasepsi. Yogyakarta: Nuha Medika

Puskesmas Uepai. (2016). Profil Puskesmas Uepai Kabupaten Konawe 2016. Uepai

Rahnu Fitri. (2012). Hubungan Faktor Predisoposisi, faktor pemungkin, dan faktor penguat dengan pemilihan Kontrasepsi IUD. Riau.

Rukiyah. (2009). Asuhan Kebidanan 1 (Kehamilan). Jakarta: Trans Info Media

Saifuddin. (2003). Buku Pedoman Praktis Kontrasepsi. Jakarta: Bina Pustaka.

Sulistyawati. (2011). Pelayanan Keluarga Berencana. Jakarta: Salemba Medika. 